\title{
NAPL Characterization Using the Ribbon NAPL Sampler
}

by

B. D. Riha

Westinghouse Savannah River Company

Savannah River Site

Aiken, South Carolina 29808

J. Rossabi

This paper was prepared in connection with work done under the above contract number with the U.S. Department of Energy. By acceptance of this paper, the publisher and/or recipient acknowledges the U.S. Government's right to retain a nonexclusive, royalty-free license in and to any copyright covering this paper, along with the right to reproduce and to authorize others to reproduce all or part of the copyrighted paper. 


\title{
NAPL Characterization Using the Ribbon NAPL Sampler
}

\author{
Contacts \\ Brian Riha \\ Savannah River Technology Center \\ Westinghouse Savannah River Company \\ Aiken, SC 29808 \\ Voice: 803-557-7807 \\ Fax: 803-557-7803 \\ Email: brian.riha @ srs.gov \\ Carl Keller \\ Flexible Liner Underground Technologies, Ltd. \\ 6 Easy Street \\ Santa Fe NM 87501 \\ Voice: $505-455-1300$ \\ Fax: $505-455-1400$ \\ Email: ckmist @ aol.com
}


WSRC-TR-99-0259

Revision $0.0-9 / 8 / 99$

\section{NAPL Characterization Using the Ribbon NAPL Sampler}

U.S. Department of Energy Office of Technology Development

U.S. Department of Energy Savannah River Operations Office

Prepared by:

Brian Riha

Joe Rossabi

Savannah River Technology Center

Westinghouse Savannah River Company

Savannah River Site

Aiken, SC 29808

Operated by:

Westinghouse Savannah River Company

For the U.S. Department of Energy under Contract No. DE-AC09-96-SR18500 
WSRC-TR-99-0259

Revision $0.0-9 / 8 / 99$

\section{DISCLAIMER}

This report was prepared as an account of work sponsored by an agency of the United States Government. Neither the United.States Government nor any agency thereof, nor any of their employees, makes any warranty, express or implied, or assumes any legal liability or responsibility for the accuracy, completeness, or usefulness of any information, apparatus, product, or process disclosed, or represents that its use would not infringe privately owned rights. Reference herein to any specific commercial product, process, or service by trade name, trademark, manufacturer, or otherwise does not necessarily constitute or imply its endorsement, recommendation, or favoring by the United States Government or any agency thereof. The views and opinions of authors expressed herein do not necessarily state or reflect those of the United States Government or any agency thereof.

This report has been reproduced directly from the best available copy.

Available to DOE and DOE contractors from the Office of Scientific and Technical Information, P.O. Box 62, Oak Ridge, TN 37831; prices available from (615) 576-8401. 865

Available to the public from the National Technical Information Service, U.S. Department of Commerce, 5285 Port Royal Road, Springfield, VA 22161.

The methods presented in this document are patented or patent pending through the United States Patent Office. 


\section{DISCLAIMER}

Portions of this document may be illegible in electronic image products. Images are produced from the best available original document. 


\section{Contents}

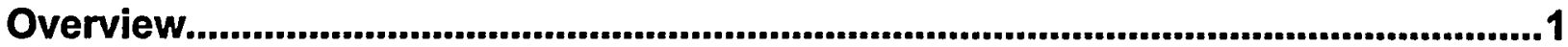

The Nature of NAPL Contamination..................................................................................1

Ribbon NAPL Sampler System..................................................................................2

Flexible Liner Underground Technologies (FLUTe) Ltd. Membrane..............................2

Hydrophobic Absorbent Ribbon .......................................................................................2

Overview of Installation Methods.........................................................................................2

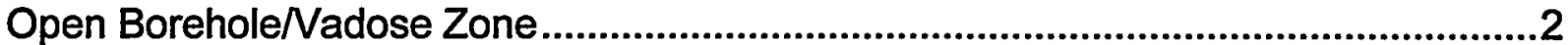

Saturated Zone and Collapsing Boreholes - CPT Method...........................................3

Other Drilling and Direct Push Methods .....................................................................4

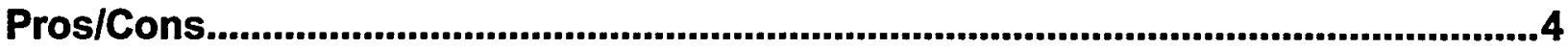

Interpretation .........................................................................................................................4

Installation Procedures .....................................................................................................10

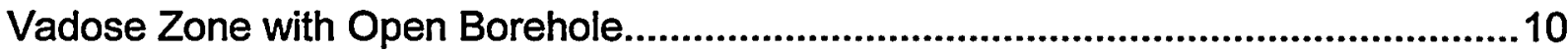

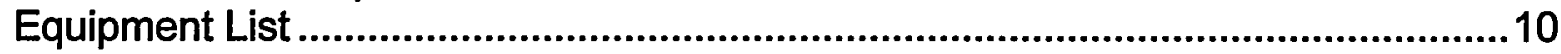

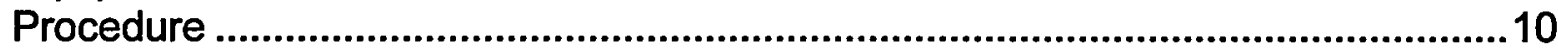

CPT Method for Saturated Zone and Collapsing Sediments...................................12

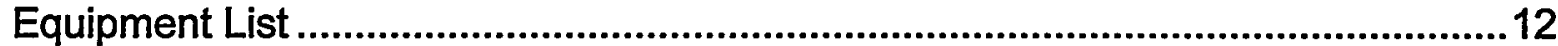

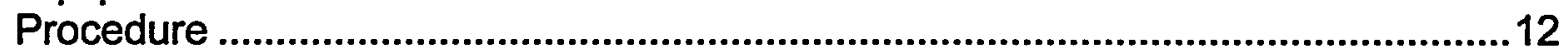




\section{NAPL Characterization Using the Ribbon NAPL Sampler Overview}

The Ribbon NAPL Sampler (RNS) is a direct sampling device that can provide detailed depth discrete mapping of Non Aqueous Phase Liquids (NAPLs - liquid solvents and/or petroleum products) in a borehole. This NAPL characterization technique uses the Flexible Liner Underground Technologies, Ltd. (FLUTe) membrane system (patent pending) to deploy a hydrophobic absorbent ribbon in the subsurface. The system is pressurized against the wall of the borehole and the ribbon absorbs the NAPL that is in contact with it. A dye, sensitive only to NAPL, is impregnated in the ribbon and turns it bright red when the contaminants are contacted. The membrane is retrieved with a tether connected to the bottom of the membrane by turning the liner inside out. At the surface, the liner is inverted and the ribbon is removed and examined. The presence and depth discrete location of DNAPL is indicated by brilliant red marks on the ribbon. Sections of ribbon can also be sent for laboratory analysis to identify the specific NAPL compounds that are present. The Ribbon NAPL Sampler can be deployed with Cone Penetrometer (CPT) or traditional drilling methods in both the vadose and saturated zones.

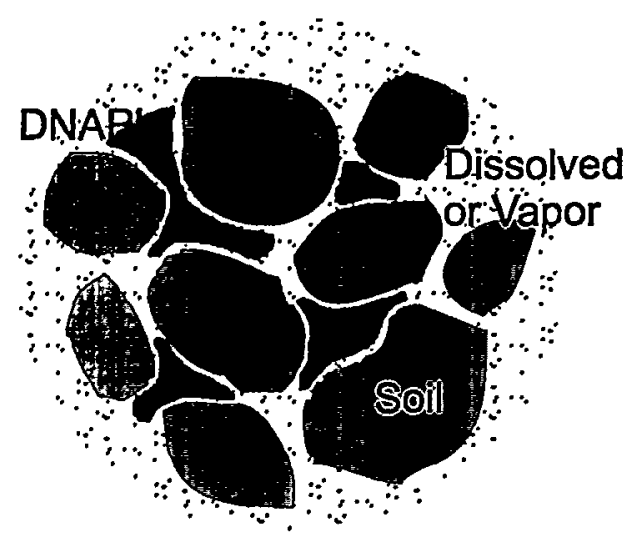

Principal DNAPLs

- Trichloroethylene (TCE)

- Perchloroethylene (PCE, tetrachloroethylene)

$-1,1,1-$ Trichloroethane (TCA)

- Dichloromethane (DCM, methylene chloride)

- Carbon Tetrachloride $\left(\mathrm{CCl}_{4}\right)$

- Creosote and Coal Tar

Principal LNAPLs

- Gasoline

-Fuel oil

- Aviation fuel

\section{The Nature of} NAPL Contamination

Dense Non Aqueous Phase Liquids (DNAPLs) such as solvents and dry cleaning fluids migrate downward and are often present in the subsurface as small discrete globules or lenses which are difficult to locate using traditional sampling methods. The Ribbon NAPL Sampler provides continuous depth discrete sampling and immediate analysis results in a borehole for the pure phase component.

Light Non Aqueous Phase Liquids (LNAPLs) such as petroleum products float on top of the water table and slowly dissolve into the groundwater. The Ribbon NAPL Sampler identifies the presence and the thickness of LNAPLs in the subsurface.

Non Aqueous Phase Liquids (NAPLs) are a long-term groundwater contamination source and are difficult to locate in the subsurface using traditional characterization methods. If the long-term source can be found, more aggressive remediation efforts can be used to clean the source and reduce the long-term impact on the aquifer and the associated costs of treating large dissolved contamination plumes. 


\section{Ribbon NAPL Sampler System}

\section{Flexible Liner Underground Technologies (FLUTe) Ltd. Membrane}

The FLUTe membrane consists of an airtight membrane liner that is pneumatically and/or hydraulically installed in a borehole. The rugged flexible tubular membrane supports and seals the borehole wall and can be installed in the saturated and vadose zones by several techniques. The membrane technology has been used to place sampling ports and sensors in varying sized boreholes to depths of $800 \mathrm{ft}$. Removal of the membrane is accomplished by turning the membrane inside out by pulling on a tether connected at the bottom of the liner. The membrane can be reused for multiple deployments.

\section{Hydrophobic Absorbent Ribbon}

The absorbent ribbon is a sleeve that covers the FLUTe membrane and is manufactured from a material that will repel water and absorb liquid solvents and petroleum products (NAPLs). This hydrophobic material readily "wicks" LNAPL and DNAPL compounds from the adjacent borehole sediments. The primary analysis method uses a hydrophobic ribbon impregnated with a powdered oil dye (Sudan IV). The dye dissolves in NAPLs that are absorbed into the ribbon and stains the ribbon bright red. The ribbon is replaceable for additional deployments with the same FLUTe membrane.

\section{Overview of Installation Methods}

\section{Open Borehole/Vadose Zone}

In non-collapsing vadose zone boreholes, the Ribbon NAPL Sampler is deployed with air pressure. The hydrophobic ribbon is attached to the membrane and the membrane is everted (turned inside out) from the canister. This eversion method prevents the ribbon from sliding along the borehole and smearing the NAPL on the membrane. The membrane is retrieved and then re-everted at the surface and inspected for the presence of NAPL. The reusable membrane is available in custom lengths and can use any length of the replaceable hydrophobic ribbon. A two-inch diameter membrane is used in CPT boreholes and other diameters are available.
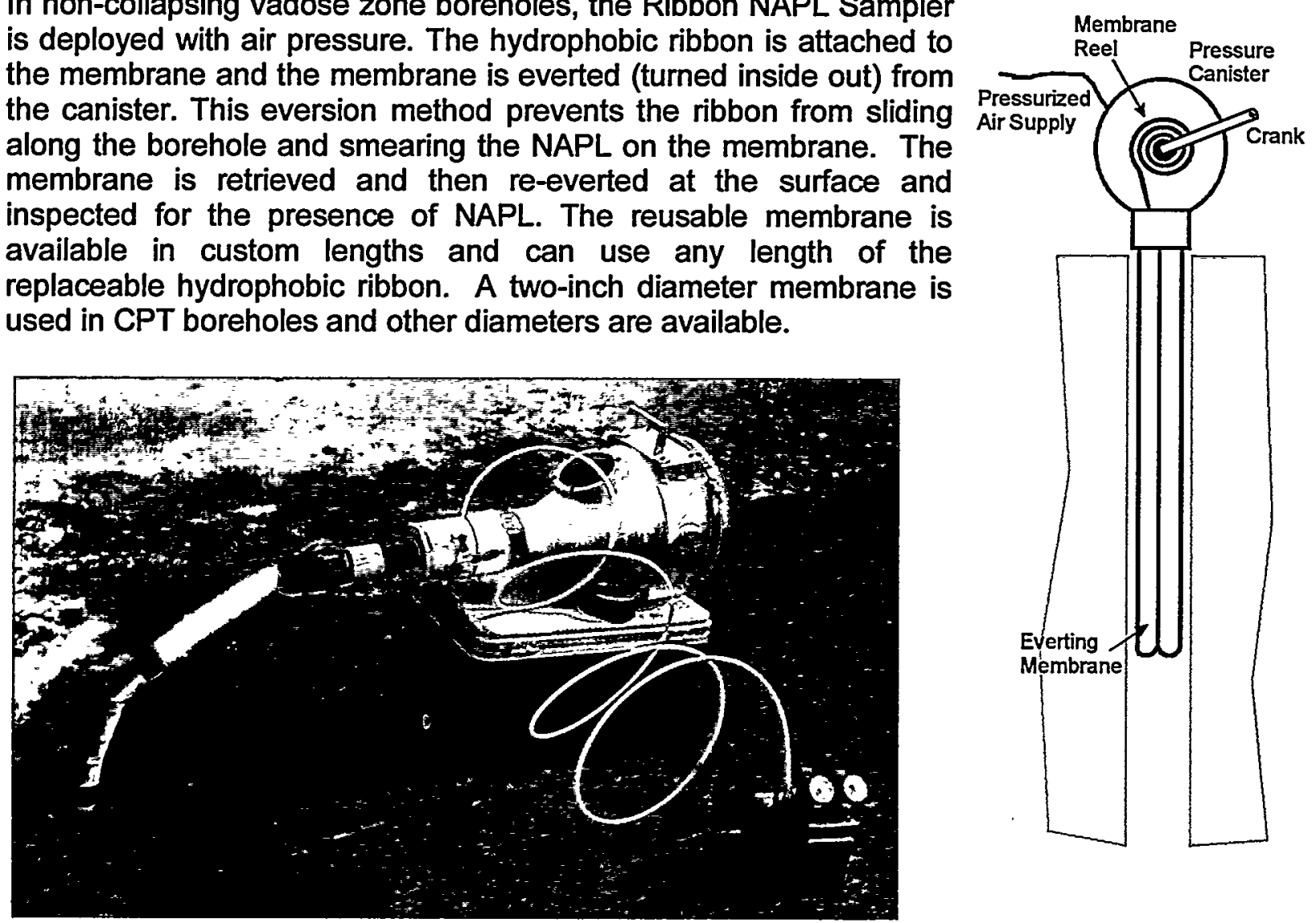
WSRC-TR-99-0259

Revision $0.0-9 / 8 / 99$

\section{Saturated Zone and Collapsing Boreholes - CPT Method}

The installation method for the Cone Penetrometer (CPT) allows for installing the Ribbon NAPL Sampler below the water table and in collapsing sediments in the vadose zone. The RNS is fabricated with a bundled ribbon around the membrane and comes assembled to specified lengths from FLUTe Ltd. The current design is for the standard CPT rods with a 1.75 inch OD and 1 inch ID. The following figures show the general configuration of the sampler and the installation concepts. The depths are limited to CPT refusal depths and are site specific and dependent on geology.

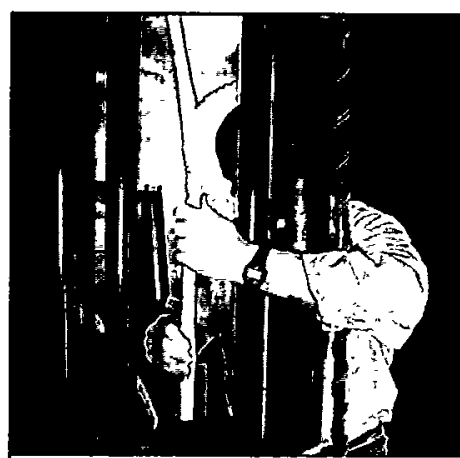

The bundled Ribbon NAPL Sampler (RNS) Is lowered into the CPT rods once the target depth has been reached.

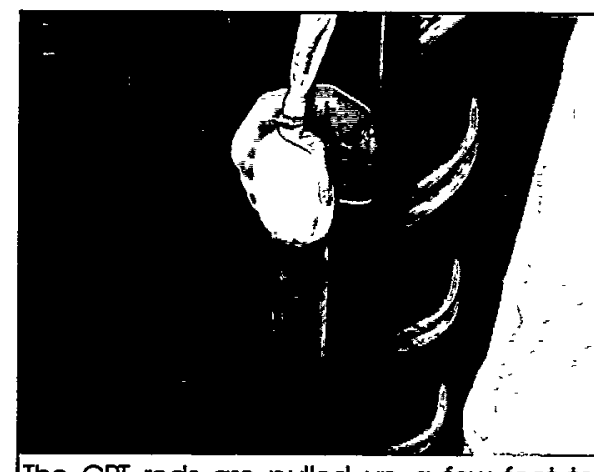

The CPT rods are pulled up a few feet to release the tip and to anchor the RNS. The RNS is pressurized inslde the rods to expand the bundled membrane.
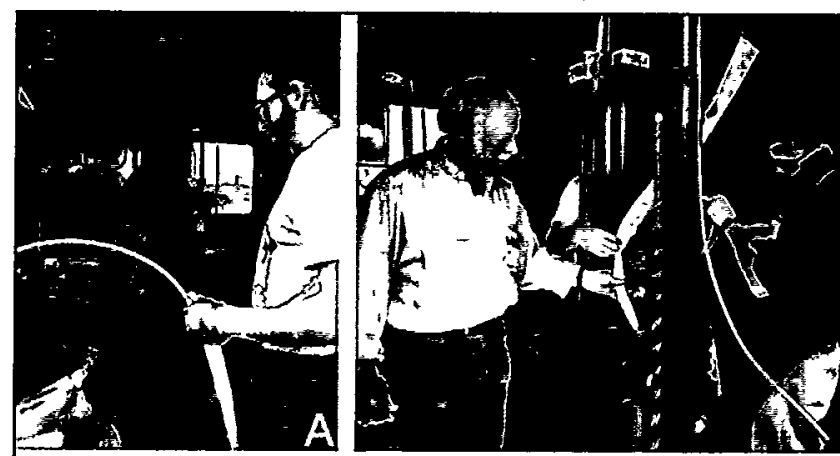

B

Water is measured Into the bottom inside of the RNS (A) to expand the membrane in the borehole as the rods are retrieved. Water is also added between the RNS and the CPT rods to balance the fluid pressures and reduce friction (B). This process continues until all the rods are retrleved and the RNS Is expanded in the borehole.

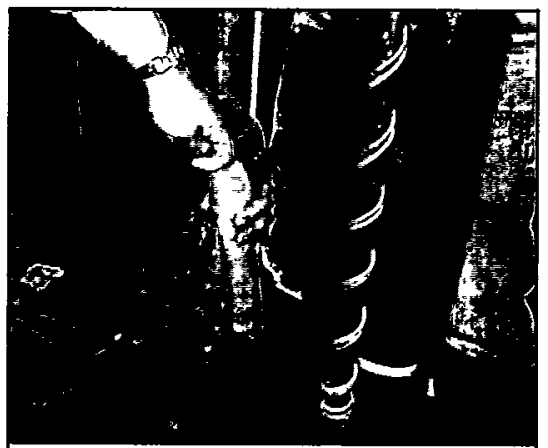

The RNS Is retrieved by pulling the tether up and turning the membrane inside out. The Inversion brings the tibbon up on the inside coway from the sediments. The waterinside the RNS is clean.

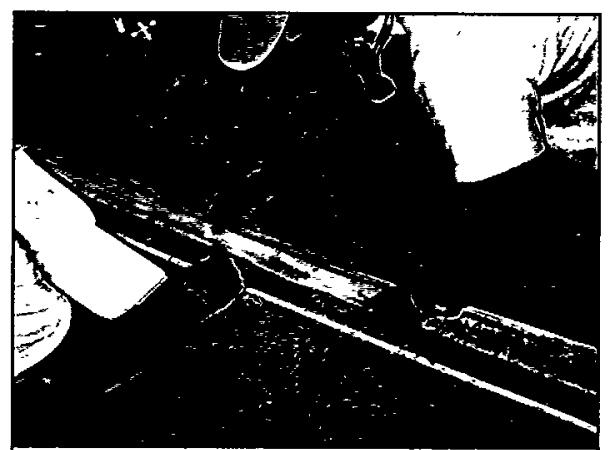

The RNS is fumed right side out and the location of depth discrete DNAPL, indicated by dyed portions of the membrane, is recorded.

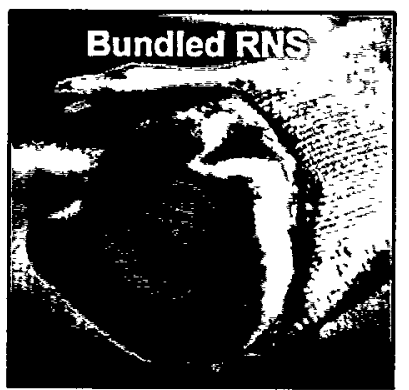

Page 3 


\section{Other Drilling and Direct Push Methods}

Other methods for deployment will require a thin cased drilling method and will follow the same procedures as the CPT method. The differences will include the size of the membrane and ribbon, the amount of water needed to fill the membrane, and a possible need to pump the water from the membrane during inversion.

\section{Pros/Cons}

\section{Pros}

Direct sampling of DNAPLs and LNAPLs Immediate field results for NAPL location Minimal waste generated

Easy and inexpensive

\section{Cons}

Membrane must be in contact with NAPL

Works for pure phase contaminants only

\section{Interpretation}

The following comments and images will aid in interpreting the ribbon for depth discrete NAPL. When the Ribbon NAPL Sampler is exposed to NAPL in the subsurface, a significant red colored staining occurs on the ribbon. The size and shape of the stains are variable and dependent on the length of time the RNS remains in the borehole and the quantity and distribution of the NAPL in the formation.

\section{General Comments on the Appearance of the Ribbon}

- A slight pink tint on an unexposed ribbon is common and normal

- Red marks from handling and storage are generally lines or finger smudges and do not have the rounded edges or brightness of the NAPL stains and are not apparent on both sides of the ribbon

- NAPL stains are generally bright red and have rounded edges consistent with the bleeding or wicking action of the dyed NAPL in the hydrophobic material and are apparent on both sides of the ribbon

- Sediments may adhere to the ribbon and will easily brush or shake off when dry staining is also visible on the clean (inside) side of the ribbon

- The brightness of the red stains will decrease over time but are still apparent 
WSRC-TR-99-0259

Revision $0.0-9 / 8 / 99$

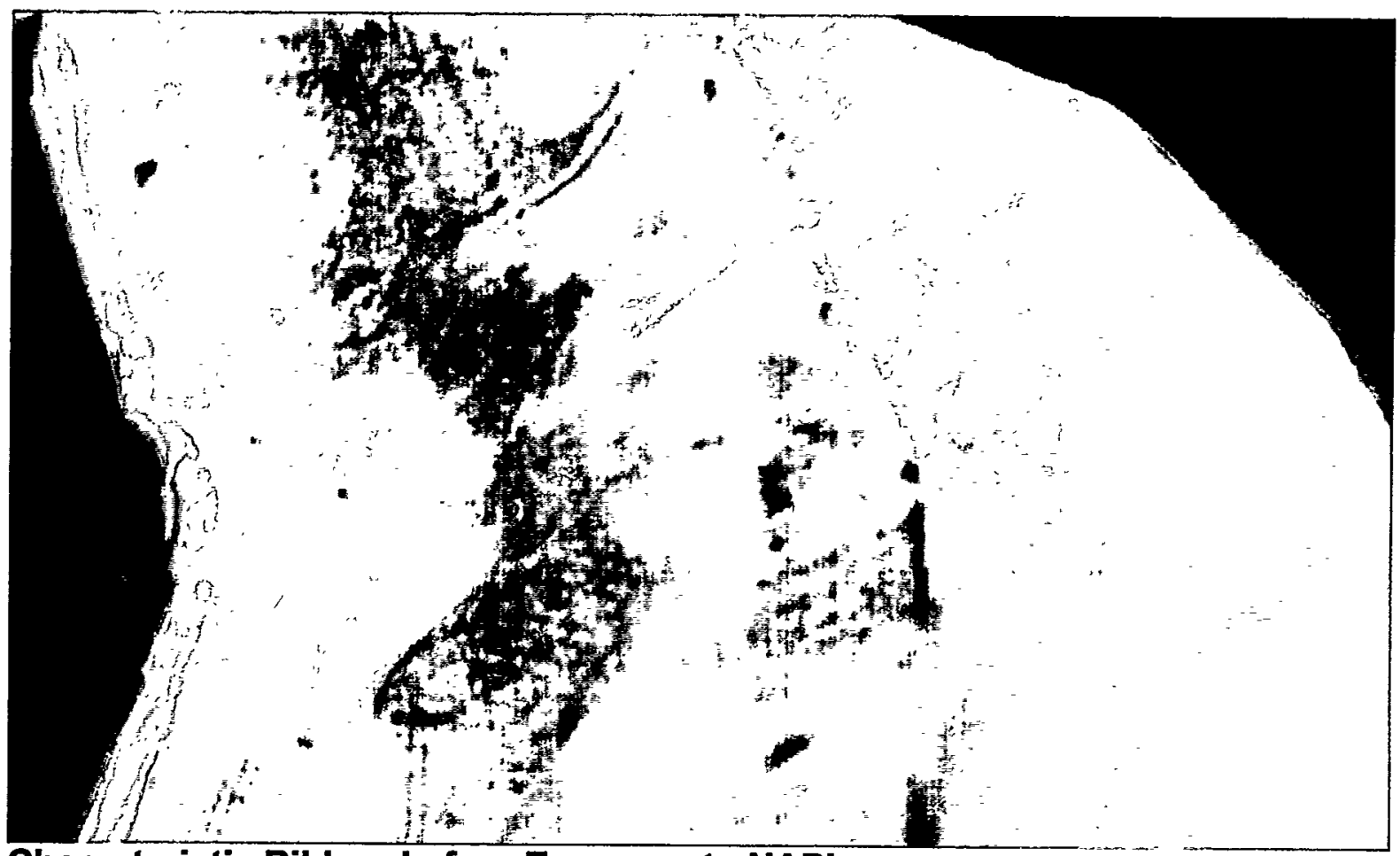

\section{Characteristic Ribbon before Exposure to NAPL}

The pink tint in some areas is normal and is significantly different from NAPL staining. The dark brownish red is the Sudan IV dye.

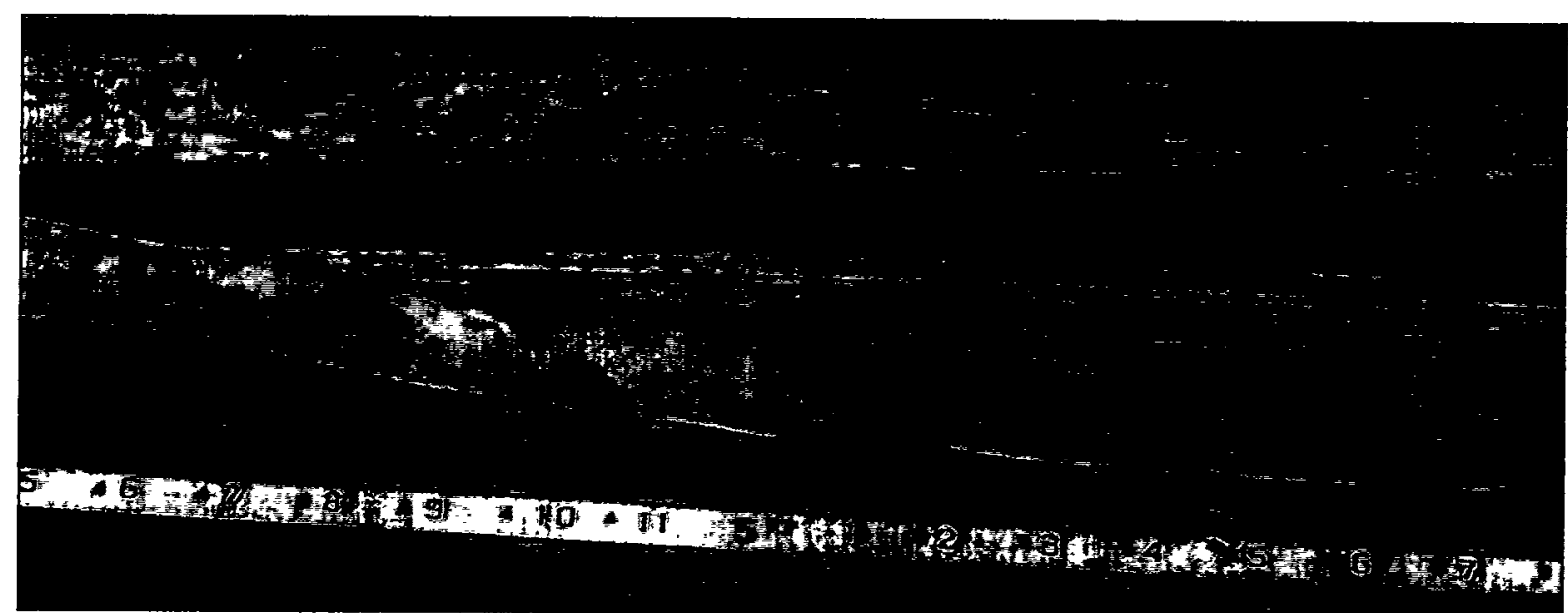

Ribbon exposed below the water table for approximately $0.5 \mathrm{hrs}$ at a TCE DNAPL site 
WSRC-TR-99-0259

Revision $0.0-9 / 8 / 99$

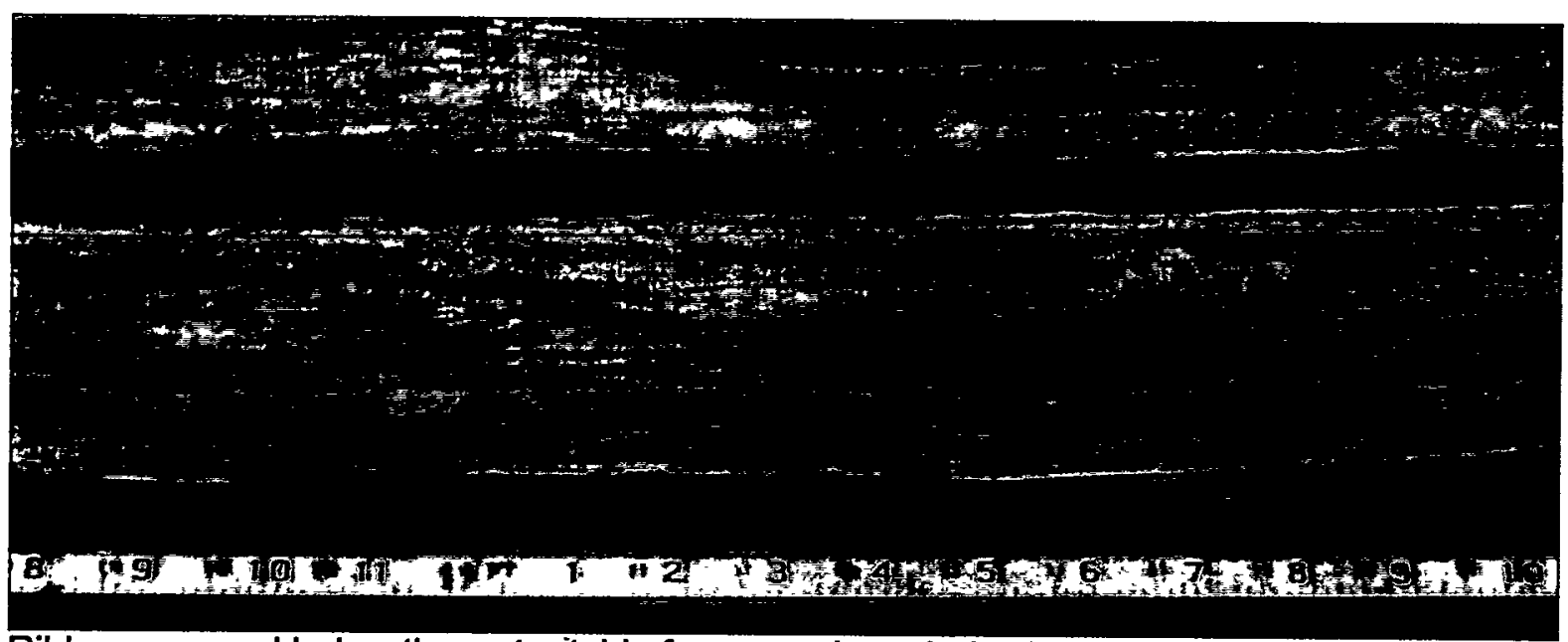

Ribbon exposed below the water table for approximately $0.5 \mathrm{hrs}$ at a TCE DNAPL site

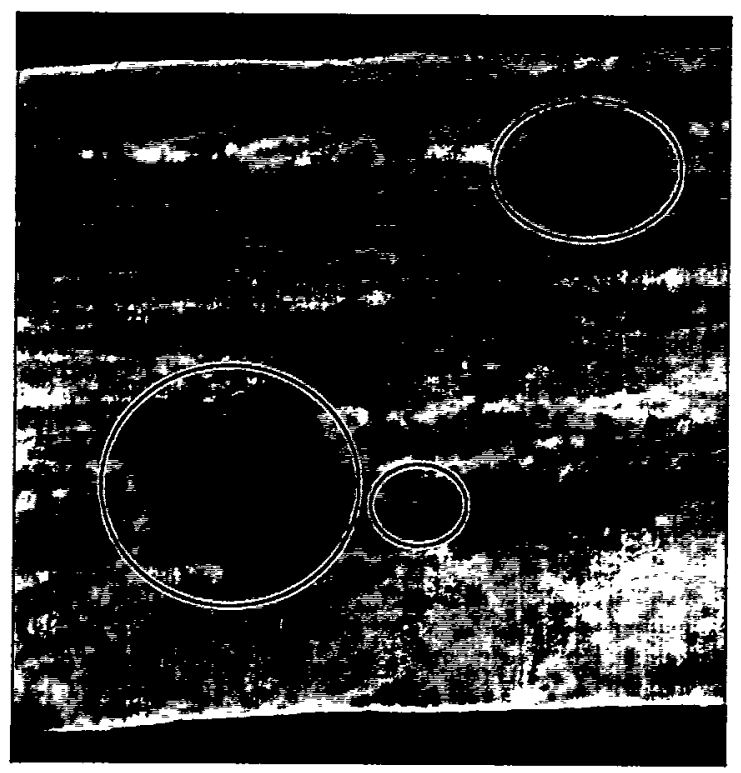

Ribbons exposed below the water table for approximately $0.5 \mathrm{hrs}$ at a TCE DNAPL site. These spots have faded 24 hrs after exposure. The stains from the DNAPL are circled.

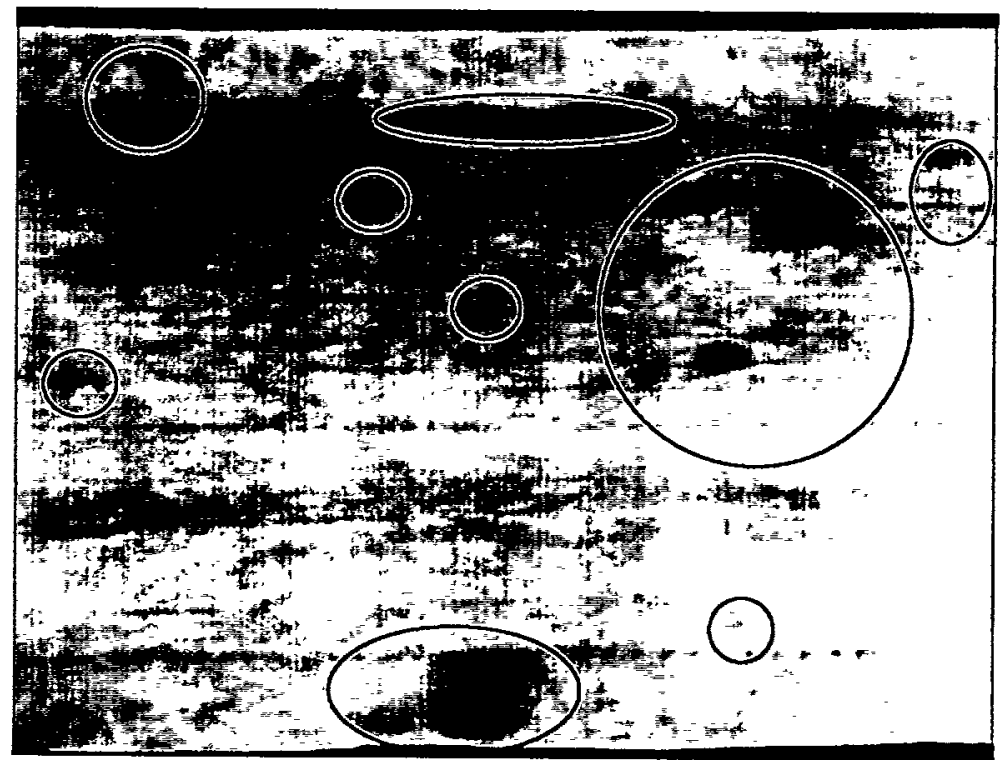



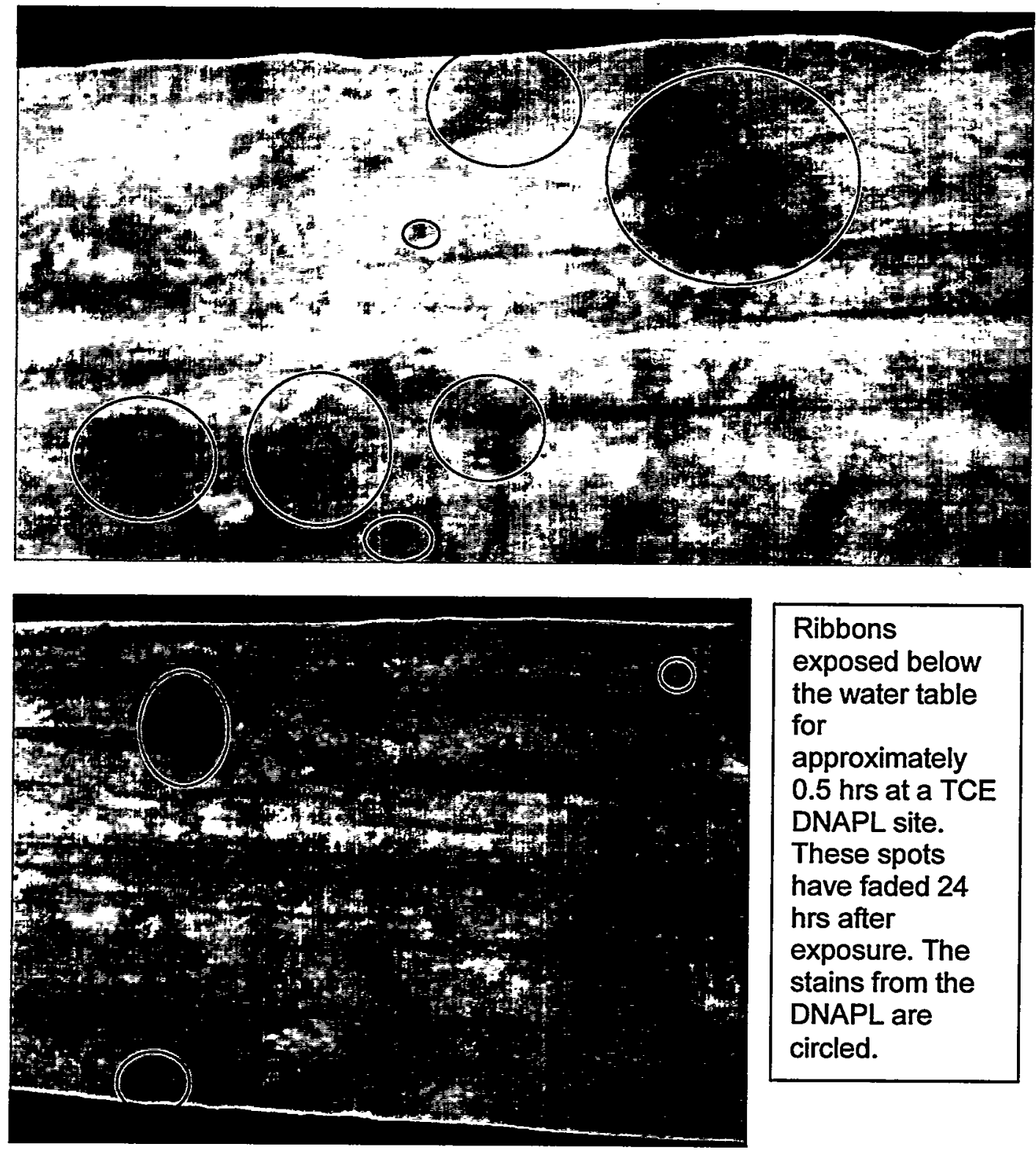

\begin{tabular}{l}
\hline Ribbons \\
exposed below \\
the water table \\
for \\
approximately \\
0.5 hrs at a TCE \\
DNAPL site. \\
These spots \\
have faded 24 \\
hrs after \\
exposure. The \\
stains from the \\
DNAPL are \\
circled.
\end{tabular}

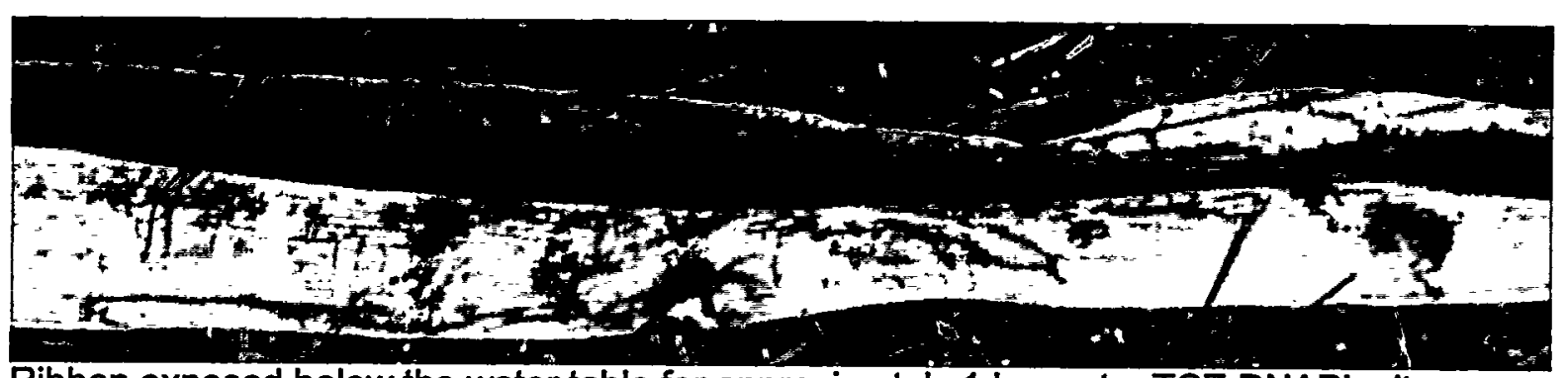

Ribbon exposed below the water table for approximately 1 hour at a TCE DNAPL site. 


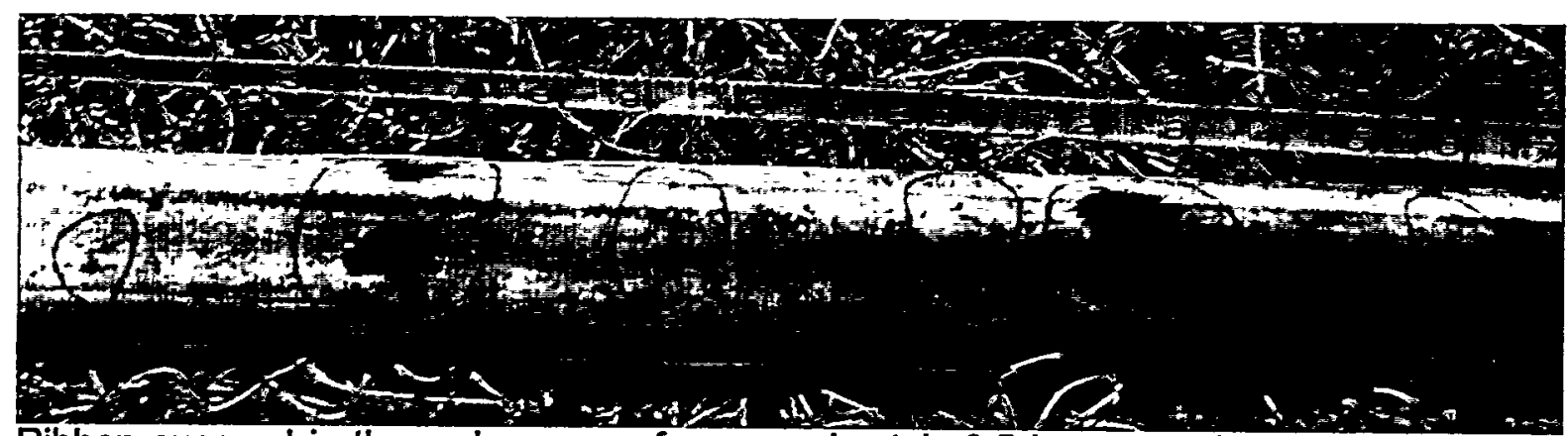
Ribbon exposed in the vadose zone for approximately 0.5 hrs at a PCE DNAPL site. The staining in the vadose zone tends to be brighter.
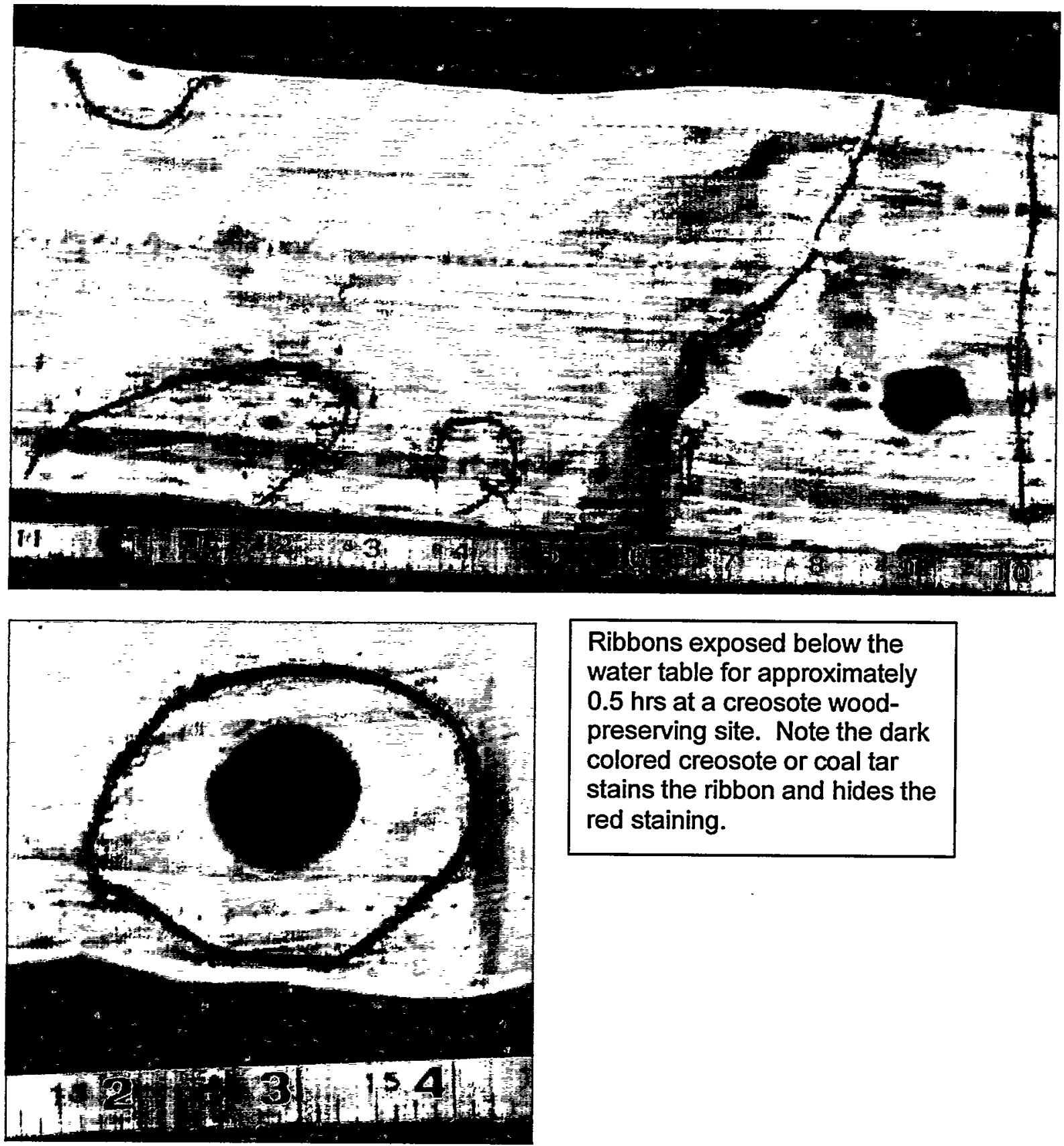

Ribbons exposed below the water table for approximately $0.5 \mathrm{hrs}$ at a creosote woodpreserving site. Note the dark colored creosote or coal tar stains the ribbon and hides the red staining. 


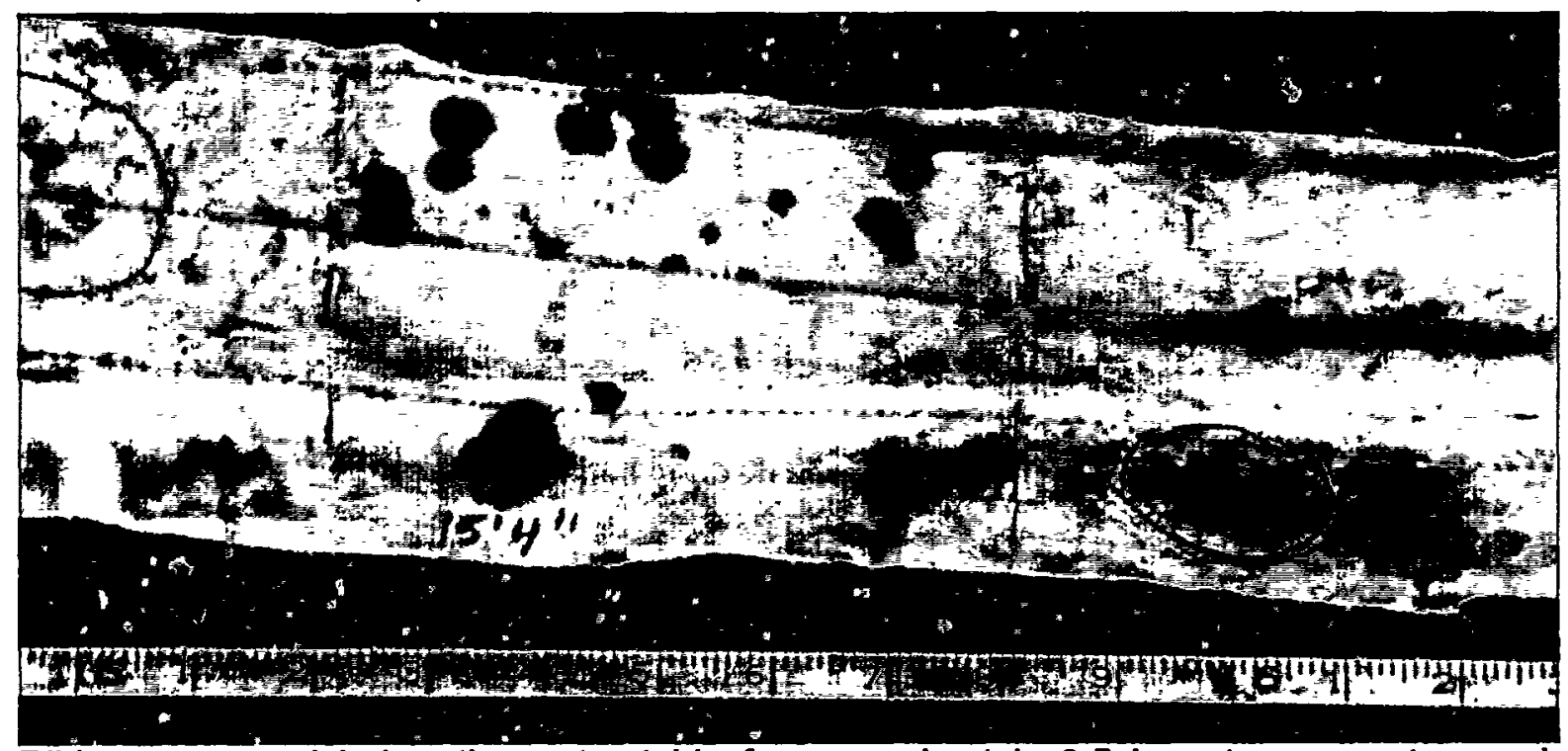

Ribbons exposed below the water table for approximately $0.5 \mathrm{hrs}$ at a creosote woodpreserving site.

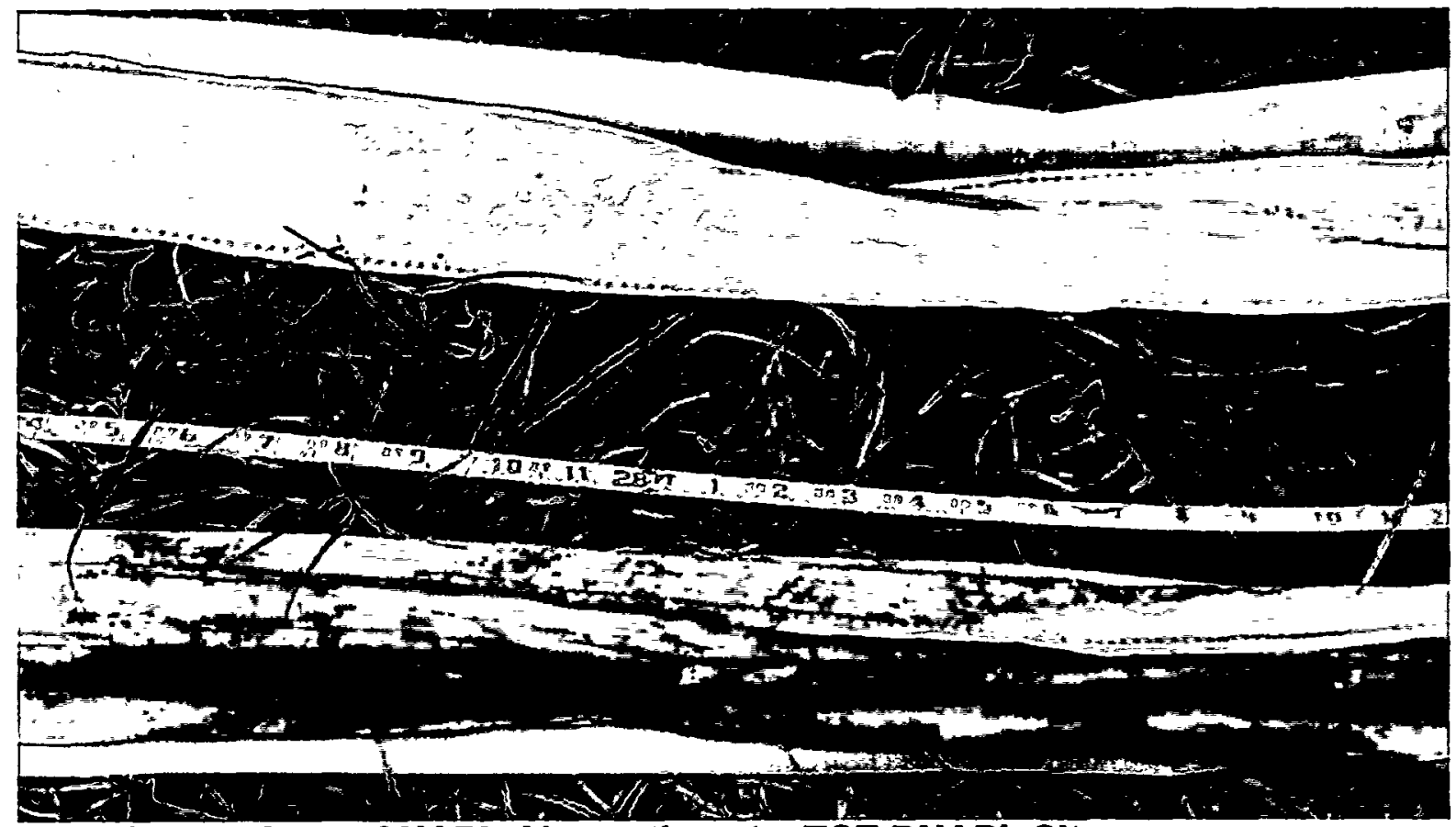

Time Comparison of NAPL Absorption at a TCE DNAPL Site

The top ribbon remained in the borehole for approximately $0.5 \mathrm{hrs}$ and the bottom ribbon for approximately $2 \mathrm{hrs}$. The boreholes were approximately $3 \mathrm{ft}(1 \mathrm{~m})$ apart. The spots on the top ribbon define the dispersed nature of the DNAPL (TCE) at the $28 \mathrm{ft}$ interval. The bottom ribbon shows the wicking and bleeding action of the hydrophobic ribbon when left in contact with the DNAPL for longer periods of time. Both ribbons delineate the DNAPL at the $28 \mathrm{ft}$ interval. 
WSRC-TR-99-0259

Revision $0.0-9 / 8 / 99$

\section{Installation Procedures}

\section{Vadose Zone with Open Borehole}

\section{Equipment List}

1. pressure canister version of the NAPL Ribbon Sampler (NRS) the size required for the open borehole ( 2 inch for CPT boreholes)

2. tubular hydrophobic ribbon

3. pressure canister with pressure gauge

4. regulated pressurized air supply capable of 20 psi and connectors to the canister (most pneumatic pumps capable of 1 scfm are sufficient)

5. 'plastic sheeting

6. tape measure

7. clean, non oily gloves for handling the sheathed liner (cotton lisle preferred, but latex can be used if well washed before use)

8. duct tape

9. assorted wrenches for fittings

\section{Procedure}

1. Load the FLUTe membrane into the canister according to the procedure provided with the membrane and canister

2. Cut off the required length of the tubular hydrophobic ribbon

3. Pressurize and extend the membrane from the canister to the distance where the membrane will enter the borehole. Use the minimum pressure required to extent the membrane. The pressure should not exceed 8-10 psi (see the procedure supplied with the FLUTe membrane for any modification to these values).

4. Slide the tubular hydrophobic ribbon over the inflated membrane a few inches and continue extending the membrane using the pressure canister inside the hydrophobic ribbon.

5. Secure the top and bottom edges of the hydrophobic ribbon to the membrane with duct tape. One to two wraps of tape will be sufficient. If too much tape is used, the membrane will be too stiff and will not invert.

6. Retract the membrane and hydrophobic ribbon into the pressure canister.

7. Complete the borehole and remove all drilling/CPT equipment.

8. Pressurize and extend the NAPL Ribbon Sampler from the canister and guide the membrane into the borehole. Use the minimum pressure required. The pressure should not exceed 8-10 psi

9. Extend the membrane to the bottom of the borehole and maintain a minimum pressure that keeps the RNS firm and pressed against the borehole.

10. Leave the RNS in contact with the formation for at least $\mathbf{3 0}$ minutes. 
11. Retract the RNS from the borehole into the canister. The ribbon is now inside the membrane. This inversion precludes cross contamination by contact with other portions of the ribbon or borehole wall.

12. Extend the RNS from the canister above ground on clean plastic sheeting.

13. Lay a tape measure along the ribbon corresponding to the borehole depth and note red stain locations for the presence of NAPLs.

14. Abandon the borehole according to the site requirements. 


\section{CPT Method for Saturated Zone and Collapsing Sediments}

\section{Equipment List}

1. NAPL Ribbon Sampler

2. CPT truck with 1 inch ID $\times 1.75$ inch OD rods

3. disposable tip that fits loosely in the bottom rod with a smooth bottom opening in the rod.

4. water addition device (e.g., 7 cup (2 liter) syringe, or a reservoir that can be water filled and pressurized with air to force the water steadily into the liner. The reservoir needs a valve to assure water addition only)

5. pressurized air supply capable of 30 psi or more

6. clean water source

7. plastic sheeting

8. tape measure

9. various connectors for water addition and air addition

10. a water measurement device such as a 8 cup ( 2 liter) beaker.

11. clean, non oily gloves for handling the sheathed liner (cotton lisle preferred, but latex can be used if well washed before use)

12. duct tape

13. a small hose clamp less than 1" od when on the liner.

14. assorted wrenches for fittings

15. funnel with about $1 / 2$ " outlet

\section{Procedure}

\section{Installation:}

1. Lay the sheathed liner out on the surface (preferably on a sheet of clean plastic) and stretch the liners and tubing, if necessary, to reduce any curl in the tubing.

2. Push the hole to depth and determine the water table depth if possible

3. Tag the water level inside the rod and the total rod depth, including the rods above the surface.

4. Mark the depth of the rods on the liner. This mark is used to insure full installation in the rod.

5. Insert the liner into the rod. If the liner will not descend the full depth, add a quart of water to the annulus and feed the liner quickly to the bottom. If the liner still needs more help, fill the annulus with water and add 0.1 cups of water per $\mathrm{ft}$. of liner in rod $(0.024$ liters/ft) to the interior to overcome the buoyancy. Push the liner to the bottom of the rod. If no water has yet been added to the interior, add about $0.1 \mathrm{cup} / \mathrm{ft}$ ( 0.024 liters/ft) to the interior to minimize the buoyancy. Record the water volume added to the interior.

6. Mark the position of the liner in the hole relative to the truck frame.

7. Fill the annulus of the rod between the liner and rod with water to compress the liner and minimize the air in the liner. 
8. Seal the top of the liner to the central tube (air tight) with tape and a hose clamp, if necessary.

9. Fill the annulus to the surface and raise the rod quickly to half the rod length to flush the liner out the bottom of the rod. If the tip has not been pulled off the rod, the liner will rise with the rod and the liner can be easily lifted to "feel" the solid tip at the bottom. (note, the tip may not come off if the annulus is not full of water).

10. Check the liner mark to see if it rose with the rod.

11. Fill the annulus completely and raise the rod quickly for its full length and remove the rod quickly. Check to assure that the liner is extended one rod length into the hole. If not, try pushing it down while adding water to the annulus. Maintain the water addition to the annulus to keep the hole open.

12. Add 8 cups ( 1.9 liters) of water to the liner with the injector. Record the water volume added to the interior.

13. Apply air pressure to the central tube of the liner to expand the bundled membrane. The pressure required to burst the seam is approximately $15 \mathrm{psi}$ above the water level pressure.

$$
\text { pressure required }(p s i)=\frac{\text { water level pressure }(f t)}{2.3 \mathrm{ft} \mathrm{H}_{2} \mathrm{O} / \mathrm{psi}}+15 \mathrm{psi}
$$

where: water level pressure is the height of the water table in $\mathrm{ft}$ above the bottom of the liner or the length of the rods if the annulus is full of water

The water head in the hole is about the pressure at which the top end of liner begins to inflate as the pressure is slowly increased. The excess pressure will burst the seam. Wait until the seam stops "popping" and then remove the pressure source. Remove the seal off the top end of the liner. At this time, the liner should be anchored in the hole by its inflated volume below the rod.

14. Add one rod hole volume ( $\sim 7$ cups, 1.7 liters) with the injector to the inside liner to dilate the liner in the hole during the next rod pull. If concerned about the friction in the rod, the 7 cups ( 1.7 liters) can be reduced to 3.5 cups ( 0.8 liters) for a half rod pull followed by another 3.5 (0.8 liters) cups for the second half. This is easily done by stopping the injection when half the water is injected.

A good indicator of the annulus being well filled is if the water spills out of the annulus at the top of the rods as the interior water is being added. (Generally, the liner fill must not raise the level inside the liner above the top of the rods. If it does, pour the water out of the top of the liner)

15. Fill the annulus with water, and lift the liner by hand to see if it is elastic (i.e., relatively free of drag in the rod). If not, add more water to the annulus and allow time for it to flow downward in the annulus. If the liner is not free in the rod, it will tear off when the rod is raised.

16. If the liner is elastic in the rod, raise one half the rod at moderate speed, keeping the annular volume filled as it rises. When the annulus is full, raise the rest of the rod length. 


\section{Remove the first rod}

18. While keeping the annulus full, add another 7 cups (1.7 liters) with the injector, check for elasticity, pull the rod steadily. Repeat for the remaining rods. If the liner starts to rise with a rod, stop and fill the annulus, then continue. After each rod is pulled, the total liner fill should be at least 7 cups ( 1.7 liters) per rod pulled. Record the water volume added to the interior.

The water added for each rod can be added during the previous rod pull. Each rod pull should not be completed without the water addition being completed. Do not get ahead of the injector. It is better to overfill the liner than to dump the annular water because too little water in the liner in the open hole can cause the borehole to collapse.

When the water addition procedure is working correctly, water will spill from the annulus when water is added to the liner and water will rise in the liner slightly. Pour off any water that rises in the liner before pulling the rods.

19. When the last rod is removed, fill the interior of the liner to the surface.

\section{Removal:}

1. Wait at least 30 minutes after the last rod is pulled.

2. Add water to fill the liner. Pull the central tube steadily to the surface to invert the liner from the hole. If the hole caved on the bottom rod exposure, the pull may be hard (50 lbs. plus) to free the bottom end of the liner. Be careful to not pull the tube so hard as to break it. The retrieval may move slowly depending on the permeability of the formation as groundwater replaces the volume left by the liner. The clean interior water will spill out the top of the liner as it is everted (this water has been inside the membrane and has not touched the formation).

3. Lay the liner on a sheet of plastic or clean grass. Hold the white ribbon sleeve while the liner is peeled off the ribbon by eversion. Lay a tape along the ribbon to show the hole depth below the surface and note any red stain locations for the presence of NAPLs. The liner can be laid adjacent to the ribbon for correlation of stains that might be on the liner.

4. Abandon the borehole according to the site requirements 